\title{
Patient Assessment of Overall Well-Being
}

National Cancer Institute

\section{Source}

National Cancer Institute. Patient Assessment of Overall Well-Being. NCI Thesaurus.

Code C121350.

A patient's estimation of the overall impact of a disease on him or herself at a given time.

Typically scored on a numeric rating scale or visual analogue scale. 